\title{
MICROORGANISMOS E SEUS METABÓLITOS UTILIZADOS NA INDÚSTRIA DE ALIMENTOS
}

\author{
Flávia De Floriani Pozza Rebello ${ }^{1}$, Arlene Gaspar ${ }^{2}$ \\ ${ }^{1}$ Professora M.Sc da IF Sul de Minas - Campus Inconfidentes, flavi.rebello@gmail.com \\ ${ }^{2}$ Professora D.Sc da Universidade Federal Rural do Rio de Janeiro (UFRRJ).
}

\section{RESUMO}

Um grande desafio para a indústria de alimentos atualmente, é atender aos anseios do consumidor, no sentido de oferecer alimentos processados, livre de aditivos químicos e submetidos a tratamentos térmicos cada vez mais brandos, a fim de que estes sejam o mais natural possível, garantindo a segurança microbiológica destes produtos. Alguns patógenos alimentares, como a Listeria monocytogenes e Escherichia coli O157:H7, bactérias extremamente nocivas à saúde, podendo levar à abortos e até mesmo ao óbito, emergiram à medida que houve um maior consumo de produtos refrigerados. Assim, há um crescente interesse pelos chamados bioconservantes alimentares. As bacteriocinas são peptídios com atividade antimicrobiana, ribossomicamente sintetizados e secretados por bactérias produzidas por diferentes cepas, principalmente as do gênero Bacillus. Essas bacteriocinas têm a capacidade de destruir ou inibir o crescimento de outras bactérias taxonomicamente relacionadas com a cepa produtora. Uma vez que as bactérias lácticas estão presentes naturalmente em produtos fermentados, suas bacteriocinas são aceitas pela legislação e pelos consumidores como aditivos alimentares. Esse trabalho de revisão tem como objetivo destacar o uso de bacteriocinas como bioconservantes em alimentos.

Palavras-chave: bioconservantes, bacteriocinas, alimentos, segurança alimentar.

\section{ABSTRACT}

A major challenge for the food industry today is to meet the desires of consumers, to offer processed foods free of chemical additives and heat-treated increasingly lenient, so that they are as natural as possible, ensuring the microbiological safety of these products. Some foodborne pathogens such as Listeria monocytogenes and Escherichia coli O157: $\mathrm{H7}$ bacteria extremely harmful to health and may lead to abortion and even to death, emerged as there was a higher consumption of chilled products. Thus, there is a growing interest in called bioconservants food. The bacteriocins are peptides with antimicrobial activity, ribosome synthesized and secreted by bacteria produced by different strains, especially those from the genus Bacillus. These substances have the capacity to destroy or inhibit the growth of other bacteria taxonomically related to the producing strain. Since the lactic acid bacteria are naturally present in fermented products, their bacteriocins are accepted by law and by consumers as food additives. This literature review has sought to highlight the use of bacteriocins as bioconservants in food.

Key - words: bioconservants, bacteriocin, food, food security.

\section{INTRODUÇÃO}

As doenças transmitidas por alimentos (DTAs) apresentam grandes índices de mortalidade, principalmente em crianças, idosos e adultos imunodeprimidos, necessitando, portanto, desenvolver 
alternativas para conservação que, associadas às tecnologias já existentes, seja possível disponibilizar à população, alimentos de melhor qualidade e mais seguros sob o ponto de vista microbiológico e toxicológico (Jay, 2000).

Com o aumento do consumo de alimentos refrigerados e congelados prontos, atendendo à demanda de mercado, aumenta também o risco do consumo de alimentos contaminados com microrganismos pscicrófilos.

Além das refeições prontas e congeladas, os consumidores atualmente têm buscado alimentos mais próximos do sabor caseiro, sem aditivos químicos e submetidos a processos térmicos mais brandos, a fim de não comprometer o sabor, aroma, aparência, cor e textura do produto.

Com o objetivo de atender as expectativas dos consumidores, as bacteriocinas e/ou seus microrganismos produtores têm sido reconhecidos como uma fonte potencial de bioconservadores para alimentos (Moreno; Lerayer; Leitão, 1999).

Praticamente todas as bactérias são capazes de produzir diversas substâncias in vitro, que podem ser inibitórias tanto para elas mesmas quanto para outras bactérias, podendo produzir efeito bactericida ou bacteriostático (Jack et al., 1995).

Diversos fatores podem ter influência sobre a atividade das bacteriocinas no alimento, tais como: mudança na solubilidade e na carga eletrostática; ligação aos componentes do alimento; inativação por proteases e mudanças na parede ou membrana celular dos microrganismos alvo como resposta a fatores ambientais (Gänzle; Weber; Hammes, 1999).

Apesar do grande número de trabalhos de pesquisa sobre a aplicação de bacteriocinas, seu uso efetivo em alimentos ainda é bastante limitado, particularmente às produzidas por Bacillus spp (Schulz; Bonelli; Batista, 2005).

Além da nisina, outras bacteriocinas já foram testadas em alimentos, principalmente produtos cárneos (Mcmullen \& Stilles, 1996; Nielsen; Dickson; Crouse, 1990) e lácteos (Buyong; Kok; Luchansky, 1998), com relativo sucesso, dentre elas a pediocina, a carnocina, a lactocina $\mathrm{S}$, as helveticinas a leuconocina $\mathrm{S}$, e a subtilisina.

A bacteriocina mais utilizada atualmente, principalmente em produtos de laticínio e embutidos cárneos é a nisina, por ser considerada segura. Porém, a segurança de outras bacteriocinas com potenciais aplicações em alimentos também tem sido avaliada.

A pediocina $\mathrm{PA}-1(\mathrm{AcH})$ foi injetada tanto em ratos como em camundongos e o teste imunológico mostrou que ela não é imunogênica para ambos os animais. Esse peptídeo também sofre proteólise pela ação da tripsina e quimiotripsina (Bhunia, 1990).

A natureza química das bacteriocinas faz com que essas substâncias sejam facilmente degradadas no trato gastrointestinal do homem e animais, muitas vezes perdendo sua toxicidade (Piard et al., 1992).

Estudos realizados com várias bacteriocinas indicaram que elas não são tóxicas nem provocam reações imunológicas e, por isso, possuem grande potencial como conservadores naturais em alimentos (Marugg ,1991).

A autorização para que uma bacteriocina seja regulamentada para uso em alimentos depende do tipo de alimento e da necessidade de sua utilização. $\mathrm{O}$ uso de bacteriocinas purificadas, microrganismos produtores de bacteriocinas, ou expressão genética de bacteriocinas em microrganismos produtores de alimentos, nos Estados Unidos está sob jurisdição da Food and DrugAdministration(FDA)esãoregulamentados como ingredientes alimentares sob o Federal Food, Drug and Cosmetic Act (FFDCA). No FFDCA, as substâncias são reconhecidas como seguras (substances generally recognaized as safe - GRAS) por especialistas. A decisão é baseada em pesquisas científicas ou no fato de tais agentes já estarem presentes historicamente sem problemas em alimentos (Fields, 1996).

A eficácia da ação de diferentes bacteriocinas foi testada em vários alimentos, principalmente produtos cárneos e lácteos, com relativo sucesso (Buyong; Kok; Luchansky, 1998, 
Giraffa; Carminati; Tarelli, 1995, Mc Mullen \& Stilles, 1996, Nielsen; Dickson; Crouse, 1990).

Estudos realizados por Van Schaik, Gahan, Hill (1999) demonstraram que Listeria monocytogenes adaptadas a ambientes ácidos são mais resistentes à ação de bacteriocinas, provavelmente devido a algumas modificações que ocorrem em sua membrana celular.

\section{NISINA}

A nisina, produzida por algumas espécies de Lactobacillus lactis subsp lactis, foi descoberta em 1928. Esta bacteriocina possui amplo espectro de ação contra bactérias Gram positivas, incluindo Listeria spp, bacilos germinativos e esporos clostridianos.
Contudo, ela não se mostra muito eficaz contra bactérias Gram negativas, bolores e leveduras. Uma possível explicação para este fato é que a parede das bactérias Gram negativas, composta por lipopolissacarídeos e proteínas, atua como uma barreira à permeabilidade celular, impedindo que a nisina atinja a membrana citoplasmática. Porém quando combinada com agentes quelantes, pressão hidrostática ou injúria celular, a nisina pode desestruturar a parede, deixando a membrana celular exposta à sua ação (De Martinis; Alves; Franco, 2002).

A Figura 1 mostra a diferença entre as paredes celulares dos organismos Gram positivos e Gram negativos.

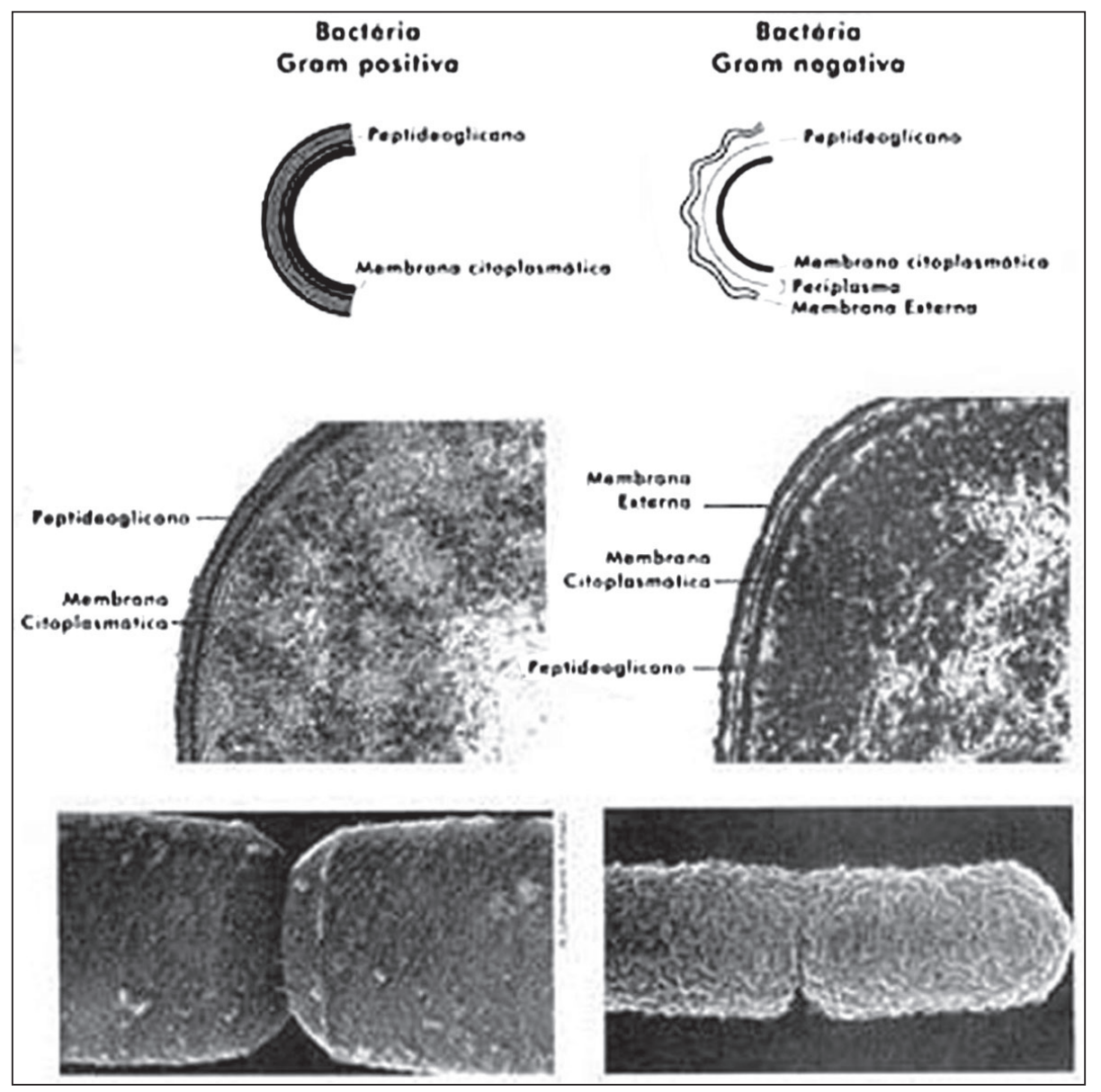

FIGURA 1 - Diferença entre as paredes celulares dos organismos Gram positivos e Gram negativos.

Fonte:<http://www.unb.br/ib/cel/microbiologia/morfologia1/morfologia1.html>Acesso em: 09fev.2010. 
Aidéia da utilização da nisina emalimentos foi sugerida pela primeira vez por Hirsch em 1951, após realização de um experimento com linhagens de Lactococcus lactis subsp. Lactis na fabricação de queijo suíço. A experiência fez com que o estufamento tardio causado por Clostridium butyricum e Clostridium tyrobutyricum fosse inibido (Delves-Broughton, 1990, Roberts; Zottola; Mickay, 1992).

Estudos de toxicidade aguda, sub-crônica, crônica, de resistência cruzada e sensibilidade alérgica indicaram que a nisina é segura para o consumo humano com uma dose diária aceitável (IDA) de $2,9 \mathrm{mg} / \mathrm{pessoa} / \mathrm{dia}$ (Food and Drug Administration, 1988).

Assim, a bacteriocina com maior uso comercial é a nisina, considerada GRAS, sendo seu uso aprovado em 47 países (Moreno, 1995).

A Tabela 1 mostra alguns exemplos de países que utilizam a nisina como bioconservante:

TABELA 1. Países que permitem o uso de nisina como bioconservante

\begin{tabular}{|c|c|c|}
\hline PAÍS & ALIMENTO & $\begin{array}{c}\text { NÍVEL MÁXIMO } \\
\text { (UI/g) }\end{array}$ \\
\hline Argentina & queijo processado & 500 \\
\hline Austrália & queijo, queijo processado e tomates enlatados & sem limite \\
\hline Bélgica & queijo & 100 \\
\hline Brasil & Queijo, vegetais enlatados e salsichas & 500 \\
\hline Estados Unidos & queijo processado e queijo pasteurizado & 10.000 \\
\hline França & queijo processado & sem limite \\
\hline Holanda & $\begin{array}{l}\text { queijo processado, queijo industrializado e queijo } \\
\text { ralado }\end{array}$ & 800 \\
\hline Inglaterra & queijo, alimentos enlatados e creme & sem limite \\
\hline Itália & queijo & 500 \\
\hline México & sem descrição & 500 \\
\hline Peru & sem descrição & sem limite \\
\hline Rússia & Queijo processado dietético e vegetais enlatados & 8.000 \\
\hline
\end{tabular}

Fonte: Cleveland et al. (2001)

De modo geral, o mecanismo de ação da nisina sobre as células de microrganismos Gram positivos ocorre em duas etapas:

A primeira, envolve a adsorção não específica da nisina sobre a parede celular desses microrganismos, fenômeno reversível e dependente do $\mathrm{pH}$. A nisina permanece sensível às proteases e o tratamento com enzimas proteolíticas protege as células sensíveis contra seu efeito letal (Carminati; Giraffa; Bossi, 1989, Cilano; Rosso; Bosso, 1991, Davies \& Adams, 1994, Hurst, 1983).

A adsorção não-específica da nisina foi verificada em diversos experimentos pela redução do título, após o contato com as células demicrorganismos sensíveis (Carminati; Giraffa; Bossi, 1989, Cilano; Rosso; Bosso, 1991, Davies \& Adams, 1994) e resistentes (Davies \& Adams, 1994). Esses estudos demonstraram, também, que a adsorção é dependente do $\mathrm{pH}$, com um valor mínimo de 3,0 (Parente; Ricciard; Addario, 1994) e um máximo de 6,5 (Yang; Johnson; Ray, 1992), da composição fosfolipídica da membrana citoplasmática dos microrganismos sensíveis (Gao; Abee; Ronings, 1991), da presença de cátions divalentes e trivalentes $(\mathrm{Mg}+2, \mathrm{Ca}+2$ 
e Gd3+) (Abee et al., 1994) e da concentração utilizada (Bruno; Kaiser; Montville, 1992).

Em uma segunda etapa, a nisina tornase insensível às proteases e as células sofrem mudanças irreversíveis. Ela seria fortemente atraída aos fosfolipídios na membrana, formando poros ou canais de $0,2-1,0 \mathrm{~nm}$ de diâmetro. A simultânea despolarizaçãoda membranacausaria um rápido efluxo de moléculas essenciais (íons $\mathrm{K}+$, aminoácidos e ATP), levando a uma série de alterações que terminariam com a lise celular (Abee et al., 1994, Bruno; Kaiser; Montville, 1992, Bruno \& Montville, 1993, Gao; Abee; Ronings, 1991, Ruhr \& Sahl, 1985, Sahl; Kordel; Benz, 1987).

A nisina foi reconhecida como aditivo alimentar pela Organização de Alimentos e Agricultura e Organização Mundial de Saúde (FAO e OMS) em 1969, com o limite máximo de ingestão de 33.000UI/Kg de peso corpóreo (Schultz; Bonelli; Batista, 2005).

É atualmente a única bacteriocina disponível comercialmente para conservação de alimentos.

No Brasil, a nisina é aprovada para uso em todos os tipos de queijos no limite máximo de $12,5 \mathrm{mg} / \mathrm{kg}$ de peso corpóreo, sendo um país pioneiro na utilização dessa bacteriocina em produtos cárneos, permitindo sua aplicação na superfície externa de salsichas de diferentes tipos.

O produto pode ser aplicado como solução comercial de nisina (Nisaplin $\left.{ }^{\circledR}\right)$ a $0,02 \%$ em solução de ácido fosfórico grau alimentício (De Martinis; Alves; Franco, 2002).

Benkerroum \& Sandine (1988) investigaram a utilização de nisina no controle de Listeria monocytogenes ATCC 7644 realizando dois experimentos. O primeiro deles, envolveu duas séries de 3 amostras cada, contendo uma mistura estéril de $250 \mathrm{~g}$ de queijo e $50 \mathrm{~mL}$ de creme pasteurizado (leite com $12 \%$ de gordura) cada uma. A primeira amostra de cada série foi destinada à adição de nisina e Listeria monocytogenes, perfazendo uma concentração final de $2,55 \times 10^{3} \mathrm{UI} / \mathrm{g}$ e $3,5 \times 10^{5}$ células/g de queijo, respectivamente. A outra amostra designada de controle positivo teve somente adição da bactéria estudada, enquanto que a terceira delas serviu como controle negativo. Dessas amostras, uma das séries foi incubada a $4^{\circ} \mathrm{C}$ e a outra a $37^{\circ} \mathrm{C}$. O segundo experimento realizado foi diferente do anterior pela não esterilização da mistura e pela temperatura de incubação, que só ocorreu a $4^{\circ} \mathrm{C}$. Os resultados revelaram que em ambos os casos, com ou sem esterilização, a presença de Listeria monocytogenes não foi detectada depois de $24 \mathrm{~h}$ nas condições estudadas, permitindo aos autores concluírem que a adição da nisina não somente inibiu o crescimento, mas também eliminou esse microrganismo.

Sabendo-se que a nisina é consumida de forma oral, Claypool et al (1966), realizaram estudos sobre os efeitos desta na microbiota oral. A partir desses estudos, foi constatado que um minuto após o consumo de leite achocolatado contendo nisina foi possível detectar apenas $40 \%$ de sua atividade quando comparada ao controle de saliva. Em contraste, o mesmo estudo mostrou que quando o leite achocolatado tinha penicilina, a saliva apresentava atividade antimicrobiana por um tempo maior.

Outro estudo mostrou o efeito das enzimas gástricas sobre a nisina; o peptídeo antimicrobiano é inativado pela tripsina e a partir disso concluiu-se que a ingestão da nisina não interfere sobre a microbiota gastrintestinal (Hara et al., 1962).

\section{DIFERENÇAS ENTRE ANTIBIÓTICOS E BACTERIOCINAS}

Antibióticos podem ser definidos como metabólitos secundários sintetizados por enzimas que apresentam aplicações clínicas. No caso das bacteriocinas, estas são proteínas ribossomicamente sintetizadas, produzidas na fase lag de crescimento microbiano, que não apresentam até o momento aplicação clínica e não alteram a microbiota do trato digestivo, pois estas são digeridas por enzimas como tripsina e 
pepsina encontradas no trato digestivo. Se as bacteriocinas fossem consideradas antibióticos, não poderiam ser utilizadas em alimentos, já que o uso de antibióticos em alimentos é ilegal
(Rosa \& Franco, 2002).

A Tabela 2 mostra resumidamente, as principais diferenças entre as bacteriocinas e os antibióticos.

TABELA 2 - Principais diferenças entre bacteriocinas e antibióticos

\begin{tabular}{|c|c|c|}
\hline CARACTERÍSTICAS & BACTERIOCINAS & ANTIBIÓTICOS \\
\hline Modo de produção & Síntese ribossomal & Sintetizados por enzimas \\
\hline Fase de produção & Metabolismo primário & Metabolismo secundário \\
\hline Mecanismo de ação & Membrana citoplasmática & Diversos \\
\hline Aplicação clínica & Não & Sim \\
\hline Resistência microbiana & Encontradas cepas resistentes & Encontradas cepas resistentes \\
\hline $\begin{array}{c}\text { Ação de enzimas proteolíticas } \\
\text { do sistema digestivo humano }\end{array}$ & São digeridas & Não são digeridos \\
\hline
\end{tabular}

Fonte: Cleveland et al. (2001)

\section{CONSIDERAÇÕES FINAIS}

O anseio do consumidor por alimentos que possam proporcionar segurança e estender sua vida útil, faz com que pesquisadores e indústrias busquem novos métodos para satisfazê-los. As bacteriocinas são uma das várias opções de métodos de controle microbiano em alimentos, podendo ser utilizadas em produtos lácteos, de panificação e em produtos cárneos. $\mathrm{O}$ estudo das bacteriocinas tem comprovado sua eficiência, desde sua descoberta, principalmente na redução desses microrganismos patogênicos, causadores de doenças veiculadas pela ingestão de alimentos contaminados, com a vantagem de não causar nenhum efeito negativo ao organismo humano, sendo eliminadas por enzimas responsáveis pela digestão. A bacteriocina mais utilizada comercialmente é a nisina, uma vez que diversos órgãos responsáveis por estudos toxicológicos em alimentos comprovaram que o uso desta é considerado seguro. Porém, é importante ressaltar que as boas práticas de fabricação ainda são fundamentais para garantir a segurança alimentar.

\section{REFERÊNCIAS BIBLIOGRÁFICAS}

ABEE,T.;ROMBOUTS, F.M.; HUGENHOLTZ, J.G.; LETELLIER, L. Mode of action of nisin against Listeria monocytogenes Scott A grown at high and low temperatures. Applied and Environmental Microbiology, Washington, v. 60, n. 6, p. 1062-1068, 1994.

BENKERROUM, N.; SANDINE, W. E. Inhibitory action of nisin against Listeria monocytogenes. J. Dairy Sci., v. 71, n. 12, p. 3237-3245, 1988.

BHUNIA, A. K. et al. Antigenic property of pediocin AcH produced by Pediococcus acidilactici H. J. Appl. Bacteriol., v. 69, p. 211215, 1990.

BRUNO, M.E.C.; KAISER, A; MONTVILLE, T.J. Depletion of proton motive force by nisin in Listeria monocytogenes cells. Applied and 
Environmental Microbiology, Washington, v. 58, n. 7, p. 2255-2259, 1992.

BRUNO, M.E.C.; MONTVILLE, T.J. Common mechanistic action of bacteriocins from lactic acid bacteria. Applied and Environmental Microbiology, Washington, v. 59, n. 9, p. 30033010, 1993.

BUYONG, L.; KOK, J.;LUCHANSKY, J.B. Use of a genetically enhanced, pediocin-producing starter culture Lactococcus lactis subsp. lactis MM217, to control Listeria monocytogenes in cheddar cheese. Appl. Environ. Microbiol., v. 64, n. 12, p. 4842-4845, 1998.

CARMINATI, D.; GIRAFFA, G.; BOSSI, M. G. Bacteriocin-like inhibitors of Streptococcus lactis against Listeria monocytogenes. J. Food Protection, Ames, v. 52, n. 9, p. 614-617, 1989.

CILANO, L.; ROSSO, D.;BOSSO, M. G. Azione di sostanze inibitrici prodotte da batteri lattici verso microrganismi patogeni. L'Industria del Latte, Lodi, v. 27, n. 3-4, p. 3-20, 1991.

CLAYPOOL, L. et al. Residence time of nisin in the oral cavity following consumption of chocolate milk containing nisin. J. Dairy Sci., v. 49, p. 314-316, 1966.

CLEVELAND, J.; MONTVILLE, T.J.; NES, I.F.; CHIKINDAS, M.L. Bacteriocins: safe, natural antimicrobials for food preservation. Int. J. Food Microbiol., v. 71, p. 1-20, 2001.

DAVIES, E.A; ADAMS, M.R. Resistance of Listeria monocytogenes to the bacteriocin nisin. Int. J. Food Microbiol., Amsterdam, v. 21, n. 4, p. 341-347, 1994.

DELVES-BROUGHTON, J. Nisin and its application as a food preservative. J. Soc. Dairy Technol., v. 43, n. 3, p. 73-76, 1990.
FOOD AND DRUG ADMINISTRATION. Nisin preparation: affirmation of GRAS status as direct human food ingredient. Fed. Register, v. 53, p. 29-33, 1988.

GÄNZLE, M. G.; WEBER, S.; HAMMES, W. P. Effect of ecological factors on the inhibitory spectrum and activity of bacteriocins. Int. J. Food Microbiol., v. 46, n. 3, p. 207 -217, 1999.

GAO, F. H.; ABEE, T.; RONINGS, W. N. Mechanism of action of the peptide antibiotic nisin in liposomes and cytochrome c-oxidase containing proteoliposomes. Applied and Environment Microbiology, Washington, v.57, n. 8, p. 2164-2170, 1991.

GIRAFFA, G.; CARMINATI, D.; TARELLI, G. T. Inhibition of Listeria innocua in milk by bacteriocin-producing Enterococcus faecium 7C5. J. Food Prot., Des Moines, v.58, n. 6, p. 621-623, June 1995.

HARA, S. et al. An investigation of toxicity of nisin with a particular reference to experimental studies of its oral administration and influences by digestive enzymes. J. Tokyo Med. Coll., v. 20, p. 176-207, 1962.

HIRSCH, A. et al. A note on the inhibition of an anaerobic sporeformer in Swiss-type cheese by a nisin-producing Streptococcus. J. Dairy Res., v. 18, p. $205,1951$.

HURST, A. Nisin and other inhibitory substances from lactic acid bacteria. In: BRANEN, A.L. DAVIDSON, P.M. Ed. Antimicrobial in Foods. Marcel Deckker Inc., New York, USA, p. 327351, 1983.

JACK, R. W.; TAGG, J. R.; RAY, B. Bacteriocins of grampositive bacteria. Microbiol. Rev., v. 39, n. 2, p. 171-200,1995.

JAY, J. M. Modern food microbiology. 6th ed. 
London: Aspen Publ., 620p, 2000.

McMUlLEN, L. M., STILLES, M. E. Potential for use of bacteriocin-producing lactic acid bacteria in the preservation of meats. J. Food Prot., p. 64-71, 1996.

MARUGG, J. D. Bacteriocins, their role in developing natural products. Food Biotechnol., v. 5, n. 3, p. 305- 312, 1991.

MORENO, I. Ocorrência e caracterização de bacteriocinas de Lactococos e sua utilização no procedimento de queijo Minas Frescal. São Paulo, 1995. (Tese de Mestrado - Faculdade de Ciências Farmacêuticas- USP).

MORENO, I.; LERAYER, A. L. S.; LEITÃO, M. F.F. Detection and characterization of bacteriocin-producing Lactococcus lactis strains. Rev. Microbiol., v. 30, n. 2, p. 130-136, 1999.

NIELSEN, J. W.; DICKSON, J. S.; CROUSE, J. D.Use of a bacteriocin produced by Pediococcus acidilactici to inhibit Listeria monocytogenes associated with fresh meat. Appl. Environ. Microbiol., v. 56, n. 7, p. 2142-2145, 1990.

PARENTE, E.; RICCIARD, A.; ADDARIO, $\mathrm{G}$. Influence of $\mathrm{pH}$ on growth and bacteriocin production by Lactococcus lactis subsp. lactis $140 \mathrm{NWC}$ during batch fermentation. Applied Microbiological and Biotechnology, Washington, v. 41, n. 4, p. 388-394, 1994.

PIARD, J. C. et al. Purification and parcial characterization of lacticin 481, a lanthioninecontaining bacteriocin produced by Lactococcus lactis subsp lactis CNR 481. Appl. Environ. Microbiol., v. 58, p. 279-284, 1992.

ROBERTS, R. F.; ZOTTOLA, E. A.; MICKAY, L. L. Use of nisin-producing starter culture suitable for Cheddar cheese manufacture. J. Dairy Sci., v. 75, n. 9, p. 2353-2363, 1992.

ROSA, C.M;FRANCO,B.D.G.M.Bacteriocinas de bactérias lácticas. Com SCIENTIAE SAÚDE. Revista Científica., UNINOVE - São Paulo, v.1 :09-15, 2002.

RUHR, E.; SAHL, H.G. Mode of action of the peptide antibiotic nisin and influence on the membrane potential of whole cells and on cytoplasmic and artificial membrane vesicles. Antimicrobial Agents Chemotherapy, v. 27, p.841-845, 1985.

SAHL, H.G.; KORDEL, M.; BENZ, R. Voltagedependent depolarization of bacterial membranes and artificial lipid bilayers by the peptide antibiotic nisin. Archives of Microbiology, v. 149, p. 120-124, 1987.

VAN SCHAIK, W.; GAHAN, C. G. M.; HILL, C. Acidadapted Listeria monocytogenes displays enhanced tolerance against the lantibiotics nisin and lacticin 3147. J. Food Prot., Des Moines, v. 62, n. 5, p. 536-539, May1999.

YANG, R.; JOHNSON, M.C.; RAY, B. Novel method to extract large amounts of bacteriocins from lactic acid bacteria. Applied and Environmental Microbiology, Washington, v. 58, n. 10, p. 3355-3359, 1992. 